\section{Study on the prevalence of Cryptosporidium in calves and HIV infected humans in the periphery of river basins of Kathmandu valley}

\author{
Paudyal S, ${ }^{1}$ Karna SR, ${ }^{2}$ Khatiwada S,1 Joshi \\ LR, ${ }^{1}$ Tiwari A, ${ }^{1}$ Shrestha SP $^{3 *}$
}

${ }^{1}$ Institute of Agriculture and Animal Science(IAAS), Tribhuvan University, Rampur, Chitwan, Nepal; ${ }^{2}$ Institute of Veterinary, Animal and Biomedical Sciences, Massey University, New Zealand; ${ }^{3}$ Animal Health Research Division, Nepal Agriculture Research Council, Khumaltar, Nepal

*Correspondence to: Dr. Swoyam Prakash Shrestha, Animal Health Research Division, Nepal Agriculture Research Council, Khumaltar, Nepal, email: swoyamsps@yahoo.com, Tel. no.: (+977)-1-5551855

\begin{abstract}
INTRODUCTION: Cryptosporidium is an important zoonotic pathogen transmitted primarily through water. This study was conducted to determine the occurrence of Cryptosporidium in calves and humans in relation to the river water in the river basins of Kathmandu.
\end{abstract}

MATERIALS AND METHODS: This cross sectional study was conducted from Sept 2012 to Feb 2013. A total of 100 fecal samples (50 calves and 50 HIV/AIDS patients living near the river basins of Kathmandu) were examined for the presence of Cryptosporidium by Ziehl-Neelsen Staining technique after Modified Sheather concentration method with centrifugation.

RESULTS: Overall $32 \%$ calves and 18\% humans were positive for Cryptosporidium oocysts, calves having higher chances of being infected than humans $(\mathrm{P}<0.05)$. The prevalence was higher in Manohara River basin than Bagmati River basin ( $\mathrm{P}$ $>0.05)$. Among calves, the samples from Manohara periphery had higher prevalence than Bagmati periphery $(\mathrm{P}<0.05)$. Likewise, the prevalence was higher in 4-6 months aged calves $(\mathrm{P}<0.05)$ and in males $(\mathrm{P}<0.05)$. Among the human samples, the females were at lower risk (odds ratio, 0.44) and 0-20 years of age group had highest prevalence (P $<0.05$ ). Humans from periphery of Manohara were at higher risk than from Bagmati (Odds ratio, 4.94).

CONCLUSIONS: Cryptosporidium has been identified in calves and HIV/AIDS patients residing in the periphery of Manohara and Bagmati river basins of Kathmandu valley suggesting the occurrence of zoonotic transmission. Cryptosporidiosis should be included in the differential diagnosis for the case of diarrhea in humans and domestic animals.

KEY WORDS: Cryptosporidum, Immuno suppression, Calves, HIV/AIDS

Article submitted 10 March. Reviewed 25 March. Author correction 28 March. Final version accepted 30 March 2013 


\section{INTRODUCTION}

Cryptosporidium Species are coccidian, oocysts forming apicomplexan protozoa, which complete their life cycle both in humans and animals, through zoonotic and anthroponotic transmission resulting in disease state called as cryptosporidiosis. Oocysts are usually transmitted by the feco-oral route, through direct host-to-host contact, and indirect contamination of food or water. Zoonotic transmission has been confirmed by epidemiological studies involving pets, farm animals and by accidental infection of veterinary workers. ${ }^{1}$ Cryptosporidium oocysts may remain viable in water for over 140 days and are very resistant to the most common disinfectants making them difficult to destroy by conventional chlorination treatment. ${ }^{1}$ Zoonotic transmission of $C$. parvum occurs through exposure to infected animals (person-to-animal contact) or exposure to water (reservoir) contaminated by feces of infected animals. ${ }^{2}$

In Nepal, the first report of human cryptosporidiosis was from a three years old boy with chronic diarrhea at Kanti Children Hospital, Kathmandu brought in relation to Rota virus infection. ${ }^{3}$ It was reported that very high prevalence of $C$. parvum was found in the different parts of Nepal such as Jomsom (17\%), Kathmandu valley (17.5\%) and Chitwan $(14.6 \%) .{ }^{4}$ Among animals, the highest prevalence was observed in deer (71\%) followed by rhino $(25 \%)$. The calves and buffalo were suffering from 34 and $37 \%$ respectively. ${ }^{5}$ River water being the main source of transmission of the parasite and the parasite being the zoonotic pathogen, this research tries to investigate the prevalence of the pathogen in calves and HIV infected people living in the same river basin. This would establish river water as an epidemiological factor for the transmission and verify the potential for the zoonotic transmission of the pathogen.

\section{MATERIALS AND METHODS}

Study Area: This was a cross sectional study carried out in 6 months period from September 2012 to Feb 2013. The cattle farms near the Bagmati and Manohara rivers had been selected purposively for this study. The farms lying within $1 \mathrm{~km}$ of the rivers were selected. The human samples were collected from the HIV infected patients living in different rehabilitation centers of Kathmandu and Lalitpur. The patients residing near river were selected as sampling population.
Collection of samples: A total of 100 samples (Fecal samples from 50 calves below 6 months age and 50 HIV/AIDS patients living near the periphery of river basins of Kathmandu) were examined for presence of Cryptosporidium. Rectal collection of the sample using the sterilized gloves was done for the animal samples whereas voluntary collection of the human samples was made. The samples were collected in the zip-lock plastic sample bags and labelled accordingly which included sample identification and site of collection. The collected samples were transported in the ice cooled sample cold box in order to maintain low temperature of the samples. The transported samples were kept in the refrigeration in the parasitology lab of Nepal Agriculture Research Council (NARC) until processing.

Processing and Staining: The samples were stained by Ziehl-Nelson (ZN) Staining technique after Modified Sheather concentration technique using centrifugation.6,7 $5 \mathrm{gm}$ of the collected faeces was put in $10 \mathrm{ml}$ of the distilled water and mixed well. $20 \mathrm{ml}$ of the supersaturated solution of $\mathrm{NaCl}$ (393 $\mathrm{gm} / \mathrm{L}$ ) was added to the solution and centrifuged at $2000 \mathrm{rpm}$ for 15 minutes after which the supernatant was taken. The final volume was made up to $100 \mathrm{ml}$ and this solution was centrifuged at $5000 \mathrm{rpm}$ for 15 minutes. The sediment was taken using glass rod and smear on the glass slide was prepared which was air dried. The air dried glass slide was fixed with methanol and set for staining. Smear was stained with unheated carbol fuchsin for 7 minutes, decolorized with $3 \%$ acid alcohol for 10-15 seconds (one dip) and counter stained with $0.5 \%$ malachite green for 30 seconds. The smear was examined microscopically for oocysts.

Ethical Approval: This study was carried out as a part of partial fulfillment of degree of Bachelor of Veterinary Science and Animal Husbandry (B.V.Sc \& A.H) and Approved by Institute of agriculture and animal Science (IAAS) internship committee. Consents of HIV/AIDS patients were taken before moving ahead to voluntary collection of their fecal samples.

Statistical Analysis: The Data entry was done using Microsoft Excel-2007 and the PHSTAT2 version 3.07 (Pearsons') was used for the analysis. Test of Independence as a type of Chi square test statistics for determining the statistical difference in Interspecies prevalence was used. ${ }^{8}$ Chi-square test of homogeneity as type of statistics for 
Table 1. Results of the explanatory variables in calves

\begin{tabular}{|c|c|c|c|c|c|}
\hline Variables & Labels & Positive & Negative & Total & $\chi 2, \mathrm{p}$-value \\
\hline \multirow[t]{2}{*}{ Location } & Manohara & 7 & 5 & 12 & $5,0.025$ \\
\hline & Bagmati & 9 & 29 & 38 & \\
\hline \multirow[t]{3}{*}{ Age(months) } & $0-20$ & 3 & 5 & 8 & $13.1,0.0014^{*}$ \\
\hline & $20-40$ & 6 & 19 & 25 & \\
\hline & $40-60$ & 7 & 10 & 17 & \\
\hline \multirow[t]{2}{*}{ Sex } & Female & 2 & 15 & 17 & $4.8,0.028^{*}$ \\
\hline & Male & 14 & 19 & 33 & \\
\hline \multirow[t]{3}{*}{ Disease State } & Lethargic & 2 & 1 & 3 &,-- 0.21 \\
\hline & Diarrhoea & 1 & 1 & 2 & \\
\hline & Asymptomatic & 13 & 32 & 45 & \\
\hline \multicolumn{2}{|c|}{ Total in each variable } & 16 & 34 & 50 & \\
\hline
\end{tabular}

Table 2. Results of explanatory variables in Humans

\begin{tabular}{|c|c|c|c|c|c|}
\hline Variables & Labels & Positive & Negative & Total & $\chi 2, p$-value \\
\hline \multirow[t]{2}{*}{ Location } & Manohara & 7 & 17 & 24 & \multirow[t]{2}{*}{$4.9^{* *}$} \\
\hline & Bagmati & 2 & 24 & 26 & \\
\hline \multirow[t]{3}{*}{ Age (years) } & $0-<20$ & 5 & 14 & 19 & \multirow[t]{3}{*}{$13.1,0.0014$} \\
\hline & $2-<40$ & 3 & 19 & 22 & \\
\hline & $40-60$ & 1 & 8 & 9 & \\
\hline \multirow[t]{2}{*}{ Sex } & Female & 2 & 16 & 17 & \multirow[t]{2}{*}{$0.4^{* *}$} \\
\hline & Male & 7 & 25 & 33 & \\
\hline \multicolumn{2}{|c|}{ Total in each variable } & 9 & 41 & 50 & \\
\hline
\end{tabular}

*indicates the difference is statistically significant at $5 \%$ level of significance, ${ }^{* *}$ Odds Ratio

Determining the statistical homogeneity in the explanatory variables like sex, age group, location, and disease status were used. ${ }^{8}$ The odds ratio and Fishers' exact test were used calculate the risk.

\section{RESULTS}

\section{Overall Microscopy results}

The microscopy revealed $18 \%(\mathrm{n}=9)$ positive cases in human samples (95\% CI, 7-28), 32\% $(n=16)$ positive cases in the calves samples (95\% CI, 19-44). The difference in prevalence between calves and human patients were statistically significant $(p>0.05 ; \chi 2,2.6)$ which suggests that cattle has higher chances of being infected followed by human beings, all living in the periphery of the river basins in Kathmandu valley. Individual prevalence of the parasite was found to be $38 \%$ and $25.1 \%$ in the periphery of Manohara and the Bagmati rivers respectively. The difference in prevalence was not statistically significant $(\mathrm{P}>0.05 ; \chi 2,3.4)$.

\section{Distribution of positive samples in calves}

Among the calves samples, 58.3\% were found to be positive from periphery of Manohara and 23.7\% were found to be positive from periphery of Bagmati (Table 1). The difference in prevalence in two river periphery was statistically significant $(\mathrm{p}<0.05 ; \chi 2,5)$ which demonstrates that the chances for infection was higher in periphery of river basin of Manohara river compared to that of Bagmati river. $11.8 \%$ of the female samples and $42.4 \%$ of the male samples were positive. The prevalence is statistically significant $(\mathrm{p}<0.05 ; \chi 2,4.8)$ which reveals that males have higher chances of acquiring the parasitic infection. From each 0-20 months, 2040 months and 40-60 months old calves, the samples were found to be $6 \%, 12 \%$ and $14 \%$ positive from each age group of the animals. The difference in prevalence was statistically significant $(\mathrm{p}<0.05 ; \chi 2,13.1)$ which tells us that some groups are more susceptible than others. Here we found that calves more than 4 months age (Weaning age) are more susceptible than other age groups. $66.7 \%$ of the depressed samples were positive, $50 \%$ of the diarrhea samples and $28.9 \%$ of the asymptomatic samples were positive. This was not statistically significant $(\mathrm{p}>0.05)$.

\section{Distribution of positive samples in Humans}

50 fecal Samples were collected voluntarily from HIV infected patients residing on the periphery of river basins of Bagmati and Manohara rivers in Kathmandu. $11.1 \%$ of the female samples were found to be positive whereas $21.8 \%$ of the male samples were found to be positive from microscopy. 
The odds ratio between the prevalence of female and male was found to be 0.4 indicating lower risk of infection in females (Table 2). Among the total 50 samples collected, each age group: 0-20 years, $20-40$ years and 40-60 years contained 10\%, 6\% and $2 \%$ of respective age group to be positive, respectively. The difference in prevalence was statistically significant $(\mathrm{p}<0.05 ; \chi 2,13.1)$ which revealed that younger age group was more susceptible to get infected with the parasite and the prevalence decreased subsequently as the age increases. $29.2 \%$ of the samples from Manohara and 7.7\% of the samples from Bagmati rivers were found to be positive from the microscopy. The odds ratio of prevalence from humans residing in Manohara and Bagmati was calculated and found to be 4.9, indicating four times higher risk of infection in Manohara river periphery than Bagmati river periphery.

\section{DISCUSSION}

The results from the calves are similar to that from Chitwan, who found out the prevalence to be $34.57 \%$ on the pre-weaned calves in Nepal. ${ }^{5}$ Swai and Schoonman also found out the prevalence to be $35 \%$ which is very near to our finding. ${ }^{9}$ This indicates that Cryptosporidium has been established in the calves from Nepal and can be related to stunted growth in calves of the weaning age group. Our finding is lower than that found in Pakistan with similar ZN staining method who found it to be $66.8 \%{ }^{10}$ Venu et al. found out $39.7 \%$ in the southern states of India. ${ }^{1}$. The higher prevalence may be due to higher specificity of molecular techniques used in these researches. Whereas, $35.5 \%$ positive samples were found in the USA as in this research even though PCR methods were used. 12

The results of age wise distribution of the parasite demonstrated that the majority of the Cryptosporidium cases were from neonates and weaning age calves. These results are in correspondence with Santin et al. and Fayer et al. who suggested that the matured dairy cattle are at low risks of infection as compared to preweaned calves. ${ }^{12,13}$ Swai and Schoonman also found out age of $>1$ to $<2$ months to be at highest risk of infection as found in our research. ${ }^{9}$ This may be due to stressed condition of the body during change in diets in first month and weaning age.

No sex preponderance was observed in Cryptosporidium infection amongst the calves. ${ }^{14,} 15$ However in the present study it was found that males were more infected when compared to female animals this may be due to careless management of male calves in Nepal. However, our result is in accordance to findings by Toroghi and Nouri who also found male to be more susceptible for the infection. ${ }^{16}$

A higher prevalence of cryptosporidiosis in diarrhoeic calves compared to non-diarrhoeic animals is reported. ${ }^{14}$ But, in the present study there was no significant difference in between diarrhoeic and non-diarrhoeic animals. However, the percentage prevalence was higher in lethargic animals (66.7\%) followed by diarrhoeic animals (50\%) and then asymptomatic animals which is similar to Mallinath et al. ${ }^{17}$ This indicates the high chances of animals to remain clinically asymptomatic animals indicated that the calves remain as reservoir and help in the shedding of parasite oocyst.

Results from this study demonstrates, $18 \%$ of the samples collected from the HIV patients residing in the river basins of Kathmandu valley to be positive for Cryptosporidium which is similar to results demonstrated in Chitwan. ${ }^{5}$ However this is higher than that reported in Kathmandu who found out $10.7 \% .^{18}$ The difference may be due to our method of sampling of the patients from periphery of river basins. The prevalence was reported to be $8.3 \%$ in the HIV patients in $\operatorname{Iran}^{19}$ which is lesser than our findings and Gupta et al. reported 25\% cases with Cryptosporidium infection in Gujarat, India ${ }^{20}$ which is higher than our findings, these may be due to different prevalence in different countries and pollution level in rivers according to location.

Findings from this research demonstrate that there is higher prevalence in HIV infected male than in female patients in Kathmandu, which is also supported by Dhakal et al. and Heidarnegadi et al. ${ }^{21,22}$ This may be due to higher mobility and activeness of the males as compared to females. The highest prevalence was demonstrated in 30-40 age group of the HIV infected patients and lowest below 20 years age which is different from this research. ${ }^{23}$ Although it is in line with Masarat et al. ${ }^{24}$ This aberration may be due to small sample size and inability to include adequate representative samples from the each age group.

\section{CONCLUSION}

This is the first research which establishes river as an epidemiological factor for the transmission of Cryptosporidium spp. in Nepal and piglets, calves and humans lie in the epidemiological cycle. Cryptosporidium was found to be prevalent in calves $(32 \%)$ and human beings $(18 \%)$ both living in the 
periphery of the river basins. Among the river basins, the animals in the Manohara river basins are more susceptible to the infection from this parasite. The stunted growth in pre-weaned calves and opportunistic infection in HIV/AIDS patient can be related to Cryptosporidium. For the accurate results regarding the prevalence and situation on the whole population, research involving adequate sample size and using molecular techniques should be carried out.

CONFLICT OF INTEREST: None to declare.

FINANCIAL INTEREST: None to declare. This research was carried out from the financial assistance provided by IAAS, office of Dean for the internship period of six months.

\section{REFERENCES}

1. Ramirez NE, Ward LA, Sreevatsan S. A review of the biology and epidemiology of cryptosporidiosis in humans and animals. Microbes Infect 2004;6:773-785.

2. Putignani L, Menichella D. Global Distribution, public health and clinical impact of the protozoan pathogen Cryptosporidium. Interdiscip Perspect Infect Dis 2010. doi:10.1155/2010/753512.

3. Sherchand JB, Larsson S, Shrestha MP, Shrestha S, Sharma PR, Adhikari R. An incidence of rotavirus and enteric adenovirus diarrhea, Kanti Children Hospital and general practitioners in the Kathmandu area. J Nepal Med Assoc 1992;30:149-59.

4. Sherchand JB, Shrestha MP, Larsson S, et al. Cryptosporidium infection and diarrhoea in children from Jomsome, Chitwan and Kathmandu valley of Nepal. Zoonosis Bull 1995;2:17-22.

5. Karna SR. Prevalence of Cryptosporidium in domestic animals (calves of cattle and buffaloes), captive elephants, wild animals (rhinoceros and deer) and HIV/AIDS patients in some villages of buffer zone of Chitwan National Park. A B.V.Sc \& A.H. Internship thesis submitted to Tribhuvan University, 2010.

6. Zajac AM, Conboy GA. Veterinary Clinical Parasitology. $7^{\text {th }}$ ed. USA: Blackwell Publishing; 2006.

7. Zhang WJ, Xu LH, Liu YY, et al. Prevalence of coccidian infection in suckling piglets in china. Veterinary Parasitology 2012;190:51-55.

8. Daniel WW. Biostatistics: a foundation for analysis in

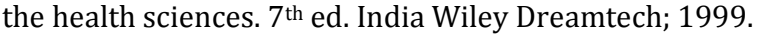

9. Swai ES, Schoonman L. Investigation into the prevalence of cryptosporidium infection in calves among small-holder dairy and traditional herds in Tanzania. Vet Med Inter 2010. doi:10.4061/2010/676451.

10. Rind RA, Robert J, Buriro R. The prevalence and incidence of Cryptosporidium species in naturally infected calves. Pak Vet J 2002;22:105-110.

11. Venu R, Latha BR, Basith SA, et al. Molecular prevalence of Cryptosporidium spp. in dairy calves in southern states of India. Vet Parasitol 2012;188:19-24. 12. Santin M, Trout JM, Xiao L. Prevalence and agerelated variation of Cryptosporidium species and genotypes in dairy calves. J Vet Parasitol 2004;122:103117.

13. Fayer R, Santin M, Trout JM. Prevalence of Cryptosporidium species and genotypes in mature dairy cattle on farms in eastern United States compared with younger cattle from the same locations. J Vet Parasitol 2007; 145:260-266.

14. Rehaman AS. Sanyal SC, Al-Mahmud KA, Sobhan A. Cryptosporidium diarrhoea in calves and their handlers in Bangladesh. Indian J Med Res 1985;82:510-516.

15. Shobhmani B. Epidemiological studies on diarrhoea in calves with particular reference to diagnosis and treatment of cryptosporidiosis. J Vet Parasitol 2005;19:77. 16. Toroghi R. Nouri M. Asymptomatic cryptosporidiosis in cattle and humans in Iran. Vet Rec 1991;128:358-359.

17. Mallinath RHK, Chikkachowdappa PG, Gowda AKJ, D'Souza PE. Studies on the prevalence of cryptosporidiosis in bovines in organized dairy farms in and around Bangalore, South India. Vet Archiv 2009;79:461-470.

18. Ghimire P, Sapkota D, Manandhar SP Cryptosporidiosis: opportunistic infection in HIV/AIDS patients in Nepal. J Trop Med Parasitol 2004;27:7-10.

19. Yosefi, F, Rahdar M, Alavi SM, Samany A. Study on prevalence of gastrointestinal parasitic infections in HIV positive patients referred to Ahvaz Razi Hospital in 20082009. Jundishapur J Microbiol 2012;5:424-426.

20. Gupta M, Sinha M, Raizada N. Opportunistic intestinal protozoan parasitic infection in HIV positive patient in Jamnagar, Gujarat. SAARC J Tuber Lung Dis HIV/AIDS 2008;1:1-4.

21. Dhakal DN, Rajendra BC, Sherchand JB, Mishra PN. Cryptosporidium parvum: an observational study in Kanti Children Hospital, Kathamandu, Nepal. J Nepal Health Res Counc 2004;2:1-5.

22. Heidarnegadi SM, Mohebah M, Maraghi SH, et al. Cryptosporidium spp. infection in human and domestic animals. Iran J Parasitol 2012;7:53-58.

23. Taherkhani H, Fallah M, Jadidian K, Vaziri S. A study on the prevalence of Cryptosporidium in HIV positive patients. J Res Health Sci 2007;7:20-24

24. Masarat S, Ahmad F, Chisti M, Hamid S, Ahmad SB. Prevalence of Cryptosporidium species among HIV Positive asymptomatic and symptomatic immigrant population in Kashmir, India. Iran J Microbiol 2012;4:3438.

\section{Citing this article}

Paudyal S, Karna SR, Khatiwada S, Joshi LR, Tiwari A, Shrestha SP. Study on the prevalence of Cryptosporidium in calves and HIV infected humans in the periphery of river basins of Kathmandu valley.Int J Infect Microbial 2013;1(2);7-11. 